Research Journal of Applied Sciences 6 (7-12): 494-500, 2011

ISSN: $1815-932 \mathrm{X}$

(C) Medwell Journals, 2011

\title{
Assessment on Hydrological Aspects of Industrial Town: Case of Bandar Baru Nilai, Negeri Sembilan, Malaysia
}

\author{
${ }^{1}$ Kadaruddin Aiyub, ${ }^{4}$ Mohamad Suhaily Yusri Che Ngah, ${ }^{1}$ Kadir Arifin, \\ ${ }^{2}$ Jamaluddin Md. Jahi, ${ }^{1}$ Azahan Awang and ${ }^{3}$ Muhamad Rizal Razman \\ ${ }^{1}$ Faculty of Social Science and Humanities, \\ ${ }^{2}$ Institute of the Malay World and Civilization (ATMA), \\ ${ }^{3}$ Institute of Environmental and Development (LESTARI), \\ Universiti Kebangsaan Malaysia, 43600 UKM, Bangi, Selangor, Malaysia \\ ${ }^{4}$ Faculty of Humanities Science, Universiti Pendidikan Sultan Idris, \\ Tanjong Malim, Perak, Malaysia
}

\begin{abstract}
One of the basic factors for continuous economic development in tropical areas is the availability of the water supply from the forest water catchment. Hydrological characteristics analysis is important to determine the availability of water which later influences the event of flash flood, surface flow velocity, base flow and underground water retention. Hydrological characteristics analysis of industrial town of Bandar Baru Nilai (BBN) was carried out based on the topography map analysis covering an area of $416 \mathrm{~km}^{2}$ and located in sensitive highland region with various channels and basic level rivulets that are formed as rain catchment areas. In total, there are 26 ponds in the study area where 14 of it functions as rain catchment pond and flood control. Systematic long term planning by the developer at the early stage of land development in this new industrial town prevents the possibility of flood occurrences especially at the downstream of the river.
\end{abstract}

Key words: Water catchment, hydrological characteristics, morphometry, rainfall, flood control, Malaysia

\section{INTRODUCTION}

One of the basic factors for continuous economic development in tropical areas is the availability of the water supply from the forest water catchment. In Malaysia, the annual rainfall exceeds $2500 \mathrm{~mm} \mathrm{year}^{-1}$ and regarded amongst wet area in the world. However, the country still faces inadequate water supply for the use of its people. Population increase and various economic development programmes have become major contributors to the dramatic increase in demands for water sources.

Drainage basin is a column unit that has complex relationship with the entity in it which is defined as drainage patterns where precipitation through surface (runoff) and sub-surface is gathered in one measurement point under the river flow (gauging station). Drainage entities included its physiography, morphometry, geology, climate, geomorphology and also social aspects. This research intended to identify morphometry aspects and hydrological characteristics changes before and after the area has been developed. The process of identification were involved two methods; field survey for validation purpose) and with the aid of GIS in calculating various morphometry parameters. Morphometry analysis is important in drainage basin investigation (River Basin) as it will determine the availability of volume of water which later influences the flood occurrences, flash flood, surface flow velocity, basic river flow (baseflow) and underground water retention (Hewleet, 1982).

\section{PHYSICAL ASPECT OF RESEARCH AREA}

Bandar Baru Nilai (BBN) (Fig. 1) was selected as a case study because it was strategically developed as industrial town by the state government to spearhead the economic development in the Northern part of Negeri Sembilan and situated adjacent to Klang valley economic region. $\mathrm{BBN}$ is located within several neighbouring sub-basins (neighbouring catchment) thus for the purpose of morphometry and hydrological changes analysis, an area of $416 \mathrm{~km}^{2}$ were identified and selected to represented $\mathrm{BBN}$ catchment. It is necessary in order to comprehensively describe river flow directions and the meeting points of the main sub-basins as it related to the movement velocity of the river or runoff after rain in the

Corresponding Author: Kadaruddin Aiyub, Faculty of Social Science and Humanities, Universiti Kebangsaan Malaysia, 43600 UKM, Bangi, Selangor, Malaysia 


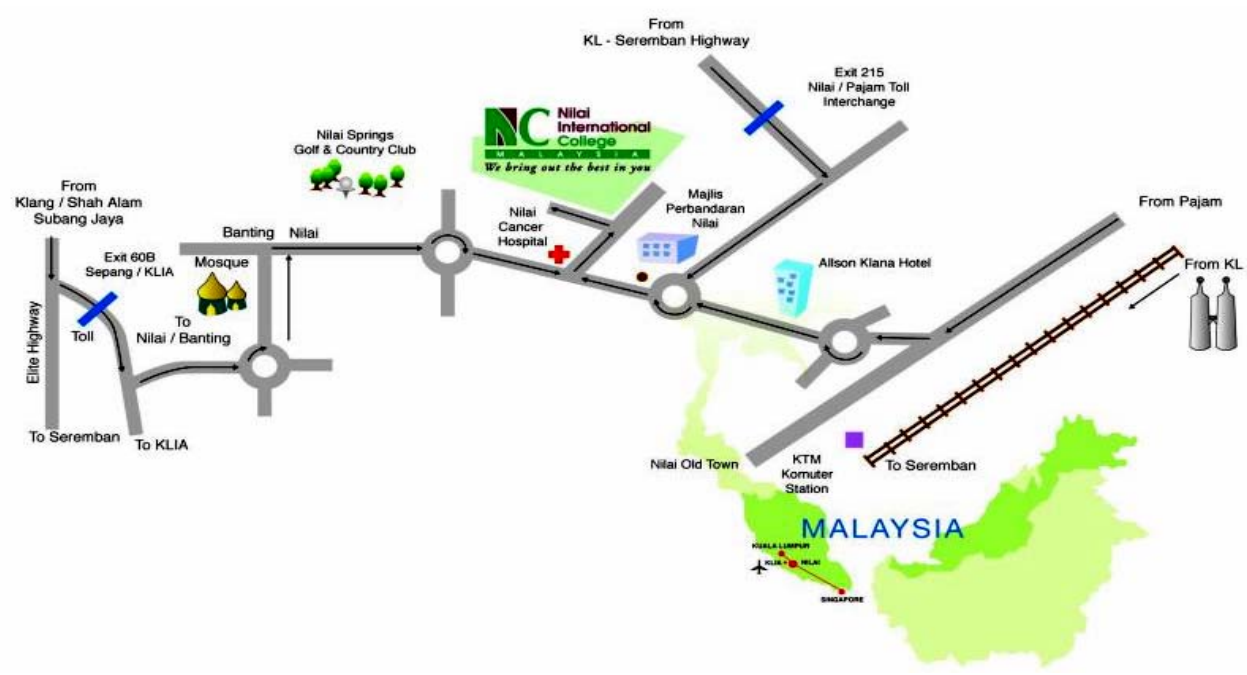

Fig. 1: Bandar Baru Nilai area

upstream. Morphometry and hydrological characteristics analysis are conducted based on 1992 topography map of Teluk Datok (sheet number 3756) and Seremban (sheet number 3856).

Specifically, the drainage basin area is located between latitude $2^{\circ} 47^{\prime} 41.66^{\prime \prime}-2^{\circ} 51^{\prime} 56.60^{\prime \prime}$ North and longitude $101^{\circ} 45^{\prime} 25.52^{\prime \prime}-101^{\circ} 50^{\prime} 21.53^{\prime \prime}$ South. The main river consists of sub-basin of Jenderam, Pajam, Buah, Mahang, Salak, Nilai-Momor-Sekah and Batang Labu. Sungai Langat is the main river which receives inflows from the above stated rivers located in the sub-basin. Sungai Jenderam, Sungai Mahang, Sungai Pajam and Sungai Buah are the main rivers in BBN which flow to the north and to the upper part of Sungai Semenyih (upper view of the map).

Even though, Sungai Salak and Sungai Nilai are closer to the basin, it first flows to the direction of Sungai Batang Labu in south before entering Sungai Langat. The discharge from rivers flowing to Sungai Langat which is located in the North will involve longer distance and will reduce water flow (lag factor) into downstream if the area is widely developed and will slow down flash flood and river overflow incidents.

The selected drainage basin is characterised by equatorial climate. It receive heavy rain during inter monsoonal season (April and October) and Southwest monsoon.

This basin received an average of $2000 \mathrm{~mm}$ rainfall annually with number of raining days in a year exceeding 150 days. Highest river order in $\mathrm{BBN}$ is order 6 which refers to main river (main trunk) namely Sungai Langat. In the area of $416 \mathrm{~km}^{2}$, there are several highest peaks exceeding $600 \mathrm{~m}$ namely in the area of Galla Forest
Reserve in the East and Setul Forest Reserve in the northern side. River network system in lowland areas are mostly between orders 4-5-6. The main river is Sungai Langat which flow from Ulu Pongsoon and two other main rivers namely Sungai Semenyih and Rinching that contribute to relatively higher river discharge to the downstream area for various human activities and for flora and fauna conservation. As for the land use at the early stage (before early 1990s), BBN area was used for plantation of rubber and oil palm to replace the primary forest.

During the end of $1990 \mathrm{~s}$, this area has been converted to industrial lands, commercial and housing which involve clearance of agricultural commodities areas and terracing of highlands areas to fulfil development demands.

\section{DATA ANALYSIS}

Rainfall is one of the important parameter in the hydrology cycle. Rainfall in tropical region specifically in Malaysia is greatly influenced by gush of monsoon wind especially during Northeast Monsoon, Southwest Monsoon and the transitional monsoon. In order to analyse rainfall variation in Nilai area, data (from the year 1961-2007) from three nearby stations was used (Table 1). These stations are monitored by Department of Irrigation and Drainage. The rainfall trend in each station showed clear variations (Fig. 1-4). Highest average annual rainfall was recorded in Ladang Labu station $(2145 \mathrm{~mm}$ ) followed by Jalan Setul station (1916.7 mm) and Astana Hinggap station $(1838.1 \mathrm{~mm})$. In average, total annual rainfall in study area is $1966.6 \mathrm{~mm}$. Time series analysis clearly 
Table 1: Rainfall monitoring station at Nilai area

\begin{tabular}{llr} 
Stationnumber & Stationname & Data uset \\
2718005 & Ltg. Labu, Labu & $1961-2007$ \\
2819002 & Bt. 8 Jalan Setul, Mantin & $1961-2007$ \\
2719043 & Astana Hinggap, Seremban & $1961-2007$ \\
\hline
\end{tabular}

Table 2: Rainfall trend, 1961-2007

Rainfall Avg. SE Min. Max. Range SD Coeff. No.

station - -

$\begin{array}{lllllllll}\text { Edg. Labu } & 2145.0 & 55 & 1101.5 & 2856.2 & 1755 & 377 & 0.18 & 47\end{array}$

$\begin{array}{lllllllll}\text { Jalan Setul } & 1916.7 & 68 & 873.0 & 2925.7 & 2053 & 468 & 0.24 & 47\end{array}$

$\begin{array}{lllllllll}\text { Astana } & 1838.1 & 73 & 571.5 & 2861.5 & 2290 & 504 & 0.27 & 47\end{array}$

Hinggap

$\begin{array}{lllllllll}\text { Rain area } & 1966.6 & 41 & 1183.0 & 2595.3 & 1412 & 284 & 0.14 & 47\end{array}$

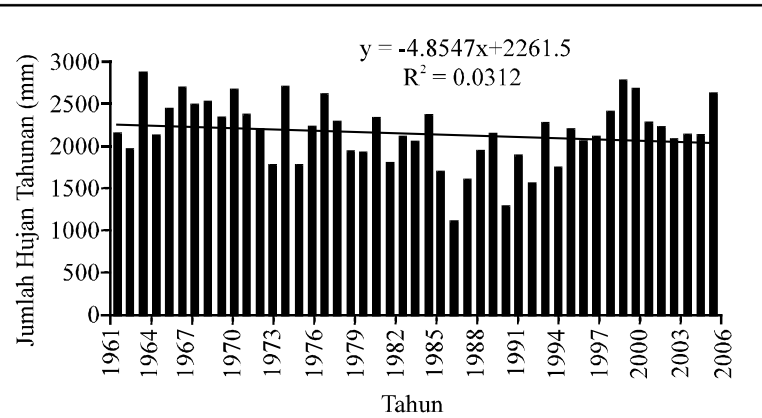

Fig. 2: Total annual rainfall at Ladang Labu, Labu $1961-2007$

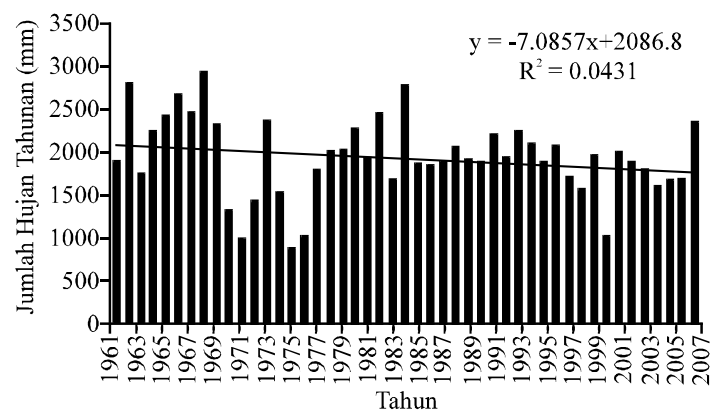

Fig. 3: Total annual rainfall at Batu 8 Jalan Setul, Mantin 1961-2007

demonstrate that the amount of rainfall in Ladang Labu station and Bt. 8 Jalan Setul station shows declining trend (Fig. 2 and 3) in long term whereas rainfall in Astana Hinggap station shows stable trend (Fig. 4). Overall, rainfall data from all three stations within the drainage basin shows declining trend for the period of 1961-2007 (Fig. 5 and Table 2).

The research area recorded an average rainfall of $1966.6 \mathrm{~mm}$ which is not exceeding the average annual rainfall in for Peninsular Malaysia which is $2400 \mathrm{~mm}$. However, the maximum rainfall recorded in every station is exceeding $2400 \mathrm{~mm}$ : Ladang Labu station- $2856.2 \mathrm{~mm}$, Bt. 8 Jalan Setul station-2925.7 $\mathrm{mm}$ and Astana Hinggap station- $2861.5 \mathrm{~mm}$. The minimum rainfall that is

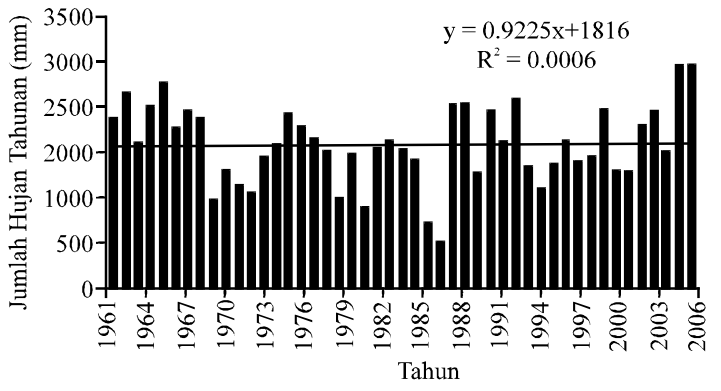

Fig. 4: Total annual rainfall at Astana Hinggap, Seremban 1971-2007

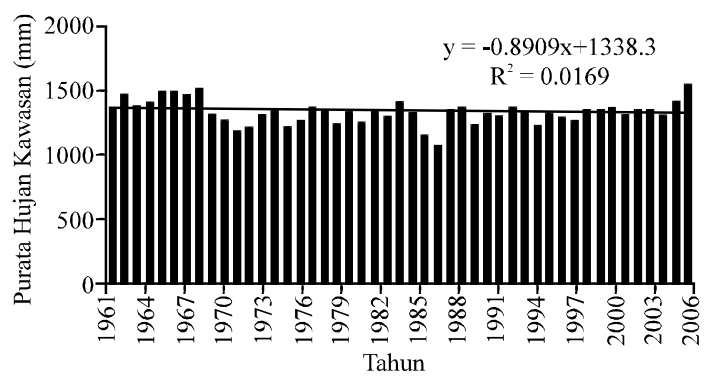

Fig. 5: Total average of annual rainfall at the study area, 1961-2007

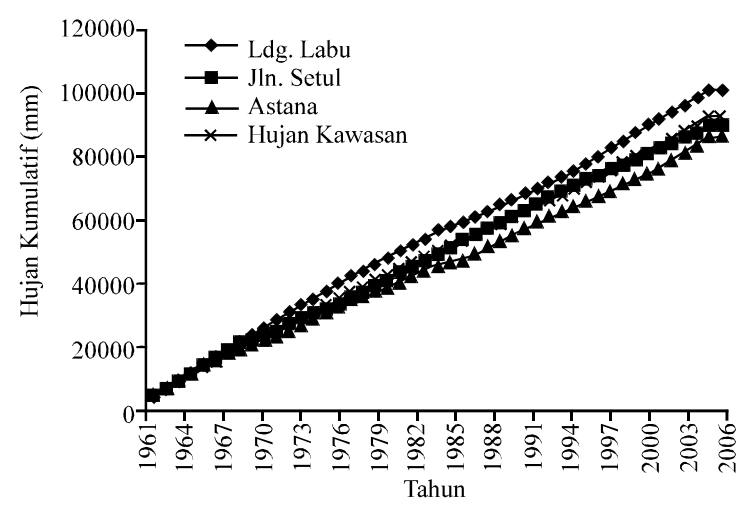

Fig. 6: Cumulative rain based on rain station and area rain 1961-2007

recorded below $1000 \mathrm{~mm}$ is at Astana Hinggap station (571.5 mm in the year 1987) and Bt. 8 Jalan Setul (873 mm in the year 1975). Rainfall variations between stations are very distinctive in the aspect of space and time effect and characterised by tropical location. Cumulative rainfalls for each station arevaried (Fig. 6), especially after the year $1970 \mathrm{~s}$ in which the cumulative line is not located at one point. This factor is related to land use change that took place after the introduction of new economy policy where forest area is developed into housing, agriculture and urbanisation process that is rapid specifically in Seremban town and Nilai. 


\section{BASIC MORPHOMETRIC ASPECT OF BANDAR BARU NILAI}

This study explains the morphometry system of drainage in the study area which involves sub-basin of Sungai Langat and Sungai Semenyih namely, Sungai Jenderam, Sungai Buah, Sungai Salak, Sungai Chelet 1, Sungai Chelet 2, Sungai Nilai-Momor-Sekah, Sungai Mahang, Sungai Pajam and other unknown sub-basins that flow into Sungai Semenyih and are named as Sungai Tanpa Nama 1 (TTN) and 2. Among the morphometric aspects that will be discussed are river order, river density, length, basin and sub-basin area and basin form.

BBN area consisted of several sub-basins which had formed a larger basin (Fig. 7) which span in an area of $416 \mathrm{~km}^{2}$. All these rivers in BBN flow to the North and South before entering the main river-Sungai Langat, located in the West. River length for each order in related to the sub-basin areas are shown in Table 3. The percentage of order 1 river in $\mathrm{BBN}$ is relatively high $(52.52 \%)$ while overall length of the river is $558.43 \mathrm{~km}$. The size BBN area is $175 \mathrm{~km}^{2}$ which consists the overall order 1 river length of $306.19 \mathrm{~km}(52.29 \%$ ) (Table 4). This fact clearly showed that BBN and its surrounding areas are located in sensitive highlands where there are many channels and basic level rivulets which act as the catchment area (water sources). Developments that are carried out in this area should consider this aspect (minimise stream fill in) to mitigate land surface from erosion and to avoid the occurrence of mud flood and flash flood.

The morphometry characteristics for each of the subbasin located in BBN are shown in Table 5. The largest sub-basins are of Sungai Pajam, $47.9 \mathrm{~km}^{2}(27 \%)$ and Jenderam, $36.6 \mathrm{~km}^{2}(21 \%)$. However, the drainage densities of both sub-basins are moderate. The area size of the catchment area greatly influences the total water volume (discharge) that is supplied into BBN drainage system. The larger the basin, the larger the water volume will be. Basins that have surface obstruction such as forest or

\begin{tabular}{|c|c|c|c|}
\hline River order & River length (km) & Percentage & Cumulative \\
\hline 1 & 558.43 & 52.52 & 53 \\
\hline 2 & 244.31 & 22.98 & 76 \\
\hline 3 & 125.27 & 11.78 & 87 \\
\hline 4 & 62.16 & 5.85 & 93 \\
\hline 5 & 40.44 & 3.80 & 97 \\
\hline 6 & 32.58 & 3.06 & 100 \\
\hline Total & 1063.19 & 100.00 & - \\
\hline
\end{tabular}

\begin{tabular}{lccc}
\multicolumn{4}{l}{ Table 4: Order and river length of main river basin in BBN } \\
\hline River order & River length $(\mathrm{km})$ & Percentage & Cumulative (\%) \\
\hline 1 & 306.19 & 52.29 & 52 \\
2 & 118.95 & 20.31 & 73 \\
3 & 59.97 & 10.24 & 83 \\
4 & 45.82 & 7.83 & 91 \\
5 & 29.26 & 5.00 & 96 \\
6 & 25.40 & 4.34 & 100 \\
Total & 585.59 & 100.00 & - \\
\hline
\end{tabular}

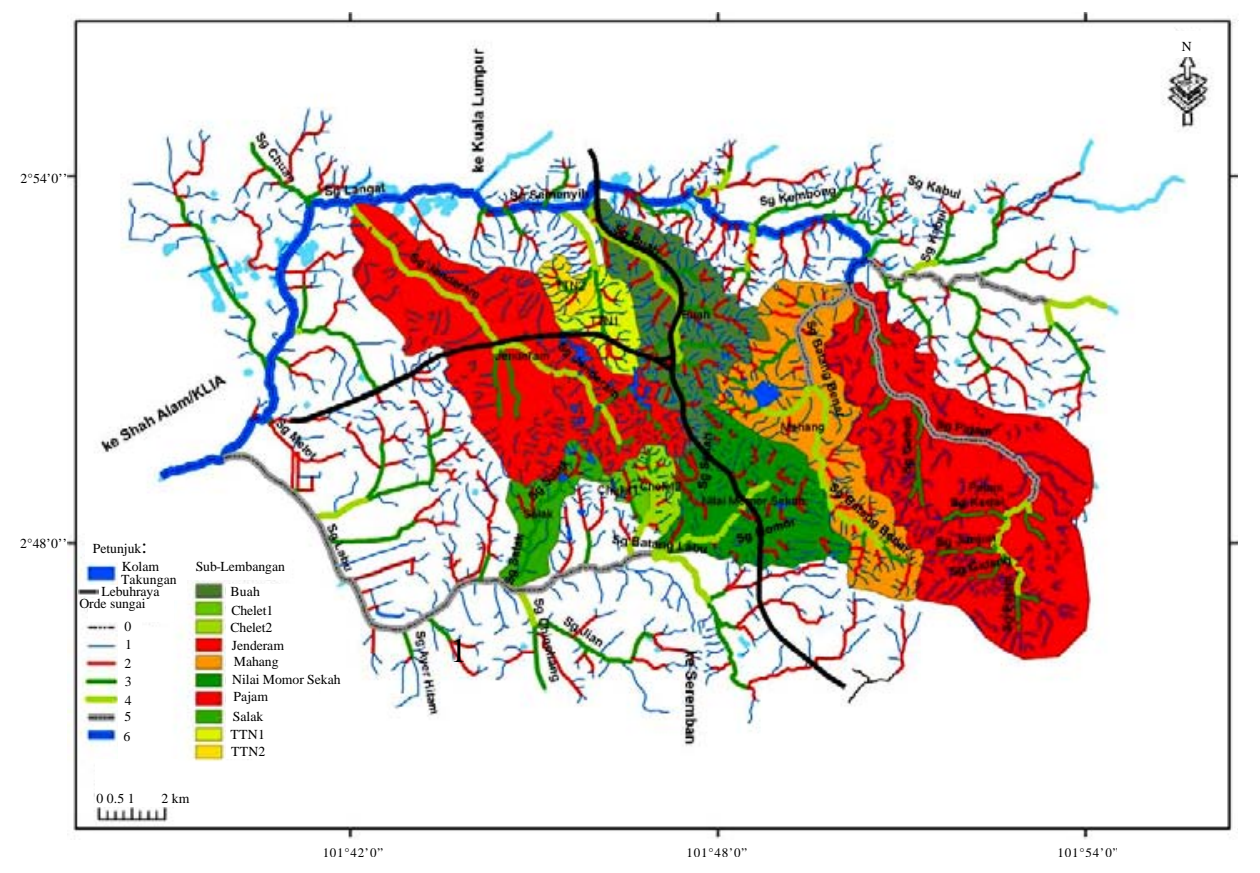

Fig. 7: Sub-basins of rivers in BBN area 
crops will entrap rain through interception and infiltration process and delay water movement. Both of the subbasins of Sungai Chelet have the highest drainage densities, 4.73 and $4.23 \mathrm{~km} \mathrm{~km}^{-2}$, espectively followed by sub-basin of Buah, $4.17 \mathrm{~km} \mathrm{~km}^{-2}$. Drainage density is so significant in the context of water availability and influence runoff speed in the event of heavy rain in which it can lead to flood occurrence (especially flash flood) when most of the land surface has been changed from natural to man-made feature. If land development in $\mathrm{BBN}$ area executed without new drainage system that environmentally friendly, it is expected that there will a decline in quality of environment in term of land erosion and deposition aspects, besides exposing the downstream area of river sub-basins to flood occurrences.

\section{RESERVOIRPONDSYSTEMATIC CONSTRUCTION}

Based on the topography map analysis, the BBN area do not have many structured reservoir such as that exists currently when the field observations were carried out. Pools that exist previously are natural swamps that are located between the meeting point of rivers order 1 and 2 in hillsides. As BBN area is in highland region, land development by the developer was systematically carried out by providing environmentally friendly drainage system to avoid impact on environment, especially in term of high capacity water discharge into river system due to the interference (fill in) of natural drainage system.
In overall, there are 26 ponds in the $\mathrm{BBN}$ area, 14 of them directly functions as rain catchment pond for flood control (Table 6 and 7). Basic infrastructure such as culvert, sediment basin, sediment pond and large/small drains are constructed systematically according to suitable specifications that fit BBN overall development planning. These aspects of drainage system preparation can be an example for town development planning although BBN is located in sensitive area based on its topography.

The reservoirs construct between several rivers especially in the sub-basins of Sungai Jenderam and Sungai Mahang are used as flood control pool. Water flow during rain or heavy rain would be stationed temporarily in this pool and later channelled to the main rivers. These pools are structurally constructed (stratified) based on the area elevation by concentrating water flow to the north (towards Sungai Semenyih). It meant to slow down water flow from directly entering the main river which can contribute to flash flood event in Southern and Western region of BBN (Fig. 8 and 9). This consideration was taken by the developer at the earlier stage of development as BBN vicinity will be develop and its natural surface will change to man-made surface (cement/ building/tar). These reservoirs also function as water body area that can minimise temperature around BBN area for recreational purposes and become the habitat for flora and fauna.

Table 5: Morphometry of all the sub-basins at BBN area

\begin{tabular}{|c|c|c|c|c|c|c|}
\hline Sub-basin & Area $\left(\mathrm{km}^{2}\right)$ & Area percentage & Area cumulative percentage & Area percentage position & Density $\left(\mathrm{km} \mathrm{km}^{-2}\right)$ & Density position \\
\hline Pajam & 47.86 & 27.35 & 27 & 1 & 2.95 & 10 \\
\hline Jenderam & 36.57 & 20.90 & 48 & 2 & 3.24 & 8 \\
\hline Mahang & 22.84 & 13.05 & 61 & 3 & 3.61 & 6 \\
\hline Buah & 17.55 & 10.03 & 71 & 4 & 4.17 & 3 \\
\hline Nilai-Momor-Sekah & 17.49 & 10.00 & 81 & 5 & 3.95 & 5 \\
\hline TTN1 & 8.72 & 4.98 & 86 & 6 & 3.61 & 7 \\
\hline TTN2 & 8.72 & 4.98 & 91 & 7 & 4.00 & 4 \\
\hline Salak & 5.55 & 3.17 & 94 & 8 & 3.14 & 9 \\
\hline Chelet1 & 5.01 & 2.86 & 97 & 9 & 4.23 & 2 \\
\hline Chelet2 & 5.01 & 2.86 & 100 & 10 & 4.73 & 1 \\
\hline Total & 175.00 & 100.00 & - & - & - & - \\
\hline
\end{tabular}

Table 6: Positions of main pools in BBN

\begin{tabular}{lcll}
\hline Latitude & Longitude & Elevation (m) & Position \\
\hline $2^{\circ} 50^{\prime} 47.31^{\prime \prime}$ & $101^{\circ} 45^{\prime} 44.06^{\prime \prime}$ & 39.93 & Size \\
$2^{\circ} 51^{\prime} 3.98^{\prime \prime}$ & $101^{\circ} 45^{\prime} 43.44^{\prime \prime}$ & 46.02 & Seside middle link \\
$2^{\circ} 50^{\prime} 48.39^{\prime \prime}$ & $101^{\circ} 46^{\prime} 25.46^{\prime \prime}$ & 58.83 & Beside middle link \\
$2^{\circ} 50^{\prime} 27.56^{\prime \prime}$ & $101^{\circ} 46^{\prime} 37.66^{\prime \prime}$ & 60.05 & USIM-Pesiaran Perdana \\
$2^{\circ} 50^{\prime} 13.37^{\prime \prime}$ & $101^{\circ} 46^{\prime} 2.75^{\prime \prime}$ & 48.16 & Small \\
$2^{\circ} 50^{\prime} 10.74^{\prime \prime}$ & $101^{\circ} 45^{\prime} 39.27^{\prime \prime}$ & 66.14 & Second largest \\
$2^{\circ} 50^{\prime} 1.49^{\prime \prime}$ & $101^{\circ} 45^{\prime} 46.22^{\prime \prime}$ & 55.47 & Medium Kasturi \\
$2^{\circ} 49^{\prime} 32.32^{\prime \prime}$ & $101^{\circ} 45^{\prime} 39.42^{\prime \prime}$ & Jalan Kasturi \\
$2^{\circ} 49^{\prime} 22.14^{\prime \prime}$ & $101^{\circ} 45^{\prime} 51.93^{\prime \prime}$ & Medium & Talan Kasturi \\
$2^{\circ} 48^{\prime} 56.52^{\prime \prime}$ & $101^{\circ} 46^{\prime} 16.96^{\prime \prime}$ & 63.66 & Taman Desa Melati Fasa 1 \\
$2^{\circ} 48^{\prime} 46.03^{\prime \prime}$ & $101^{\circ} 46^{\prime} 25.46^{\prime \prime}$ & 47.55 & Taman Desa Melati Fasa 1 \\
$2^{\circ} 49^{\prime} 19.05^{\prime \prime}$ & $101^{\circ} 45^{\prime} 27.53^{\prime \prime}$ & 39.01 & Pesiaran Kolej BBN (link) \\
$2^{\circ} 49^{\prime} 5.16^{\prime \prime}$ & $101^{\circ} 45^{\prime} 27.22^{\prime \prime}$ & 60.05 & Pesiaran Kolej BBN (link) \\
$2^{\circ} 48^{\prime} 8.53^{\prime \prime}$ & $101^{\circ} 45^{\prime} 34.01^{\prime \prime}$ & 37.80 & Desa Melati \\
\hline & & 31.09 & Desa Melati \\
\hline
\end{tabular}




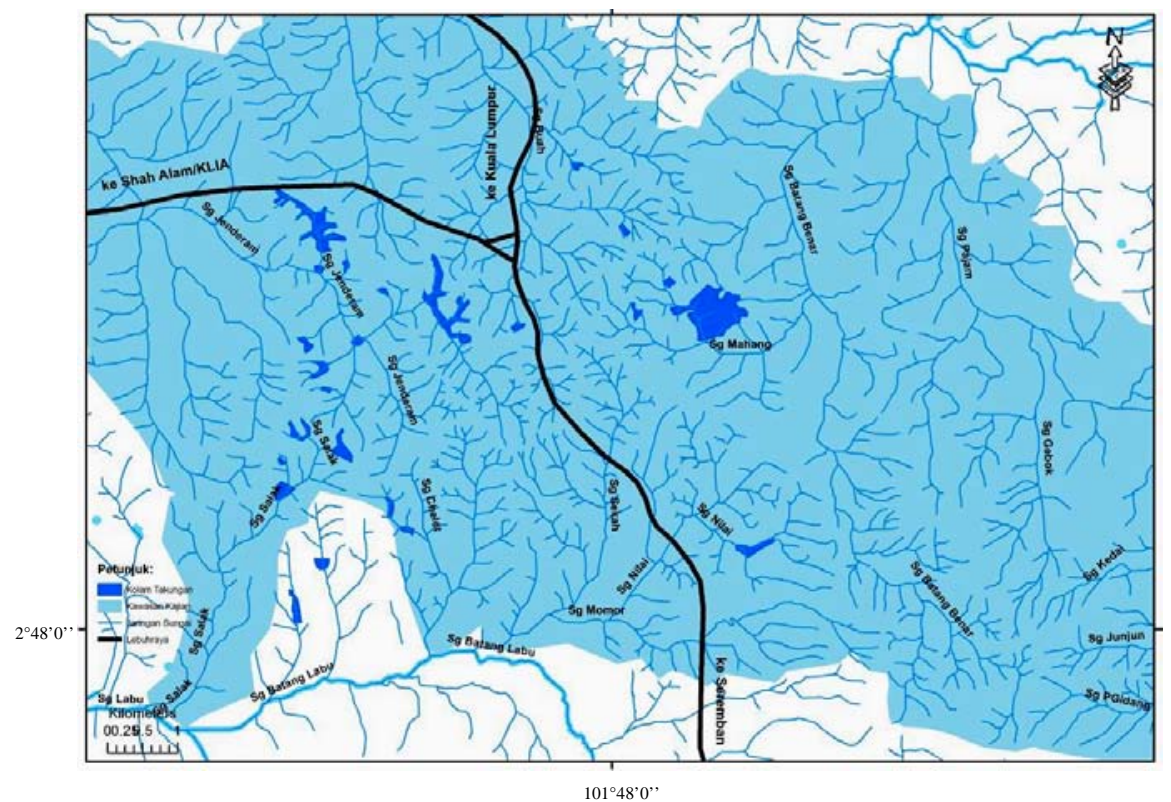

Fig. 8: Positions of reservoirs in BBN area

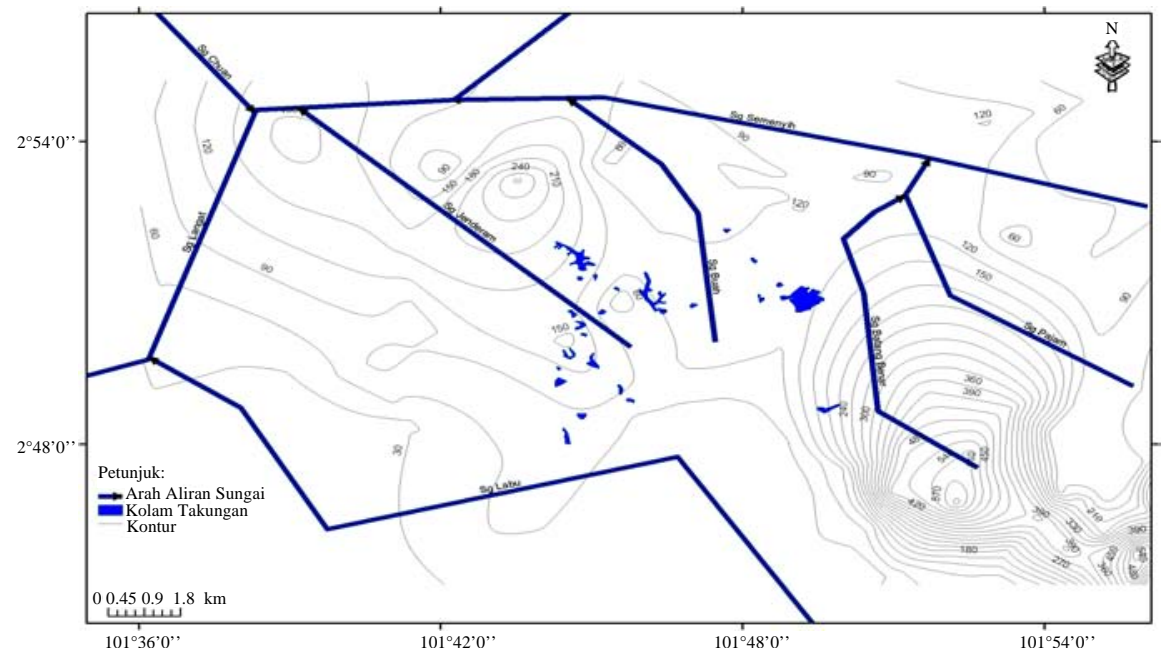

Fig. 9: Positions of reservoirs and flow directions in BBN area

Table 7: Positions of other pools in BBN

\begin{tabular}{lcc}
\hline Latitude & Longitude & Elevation $(\mathrm{m})$ \\
\hline 2.83 & 101.76 & 62.48 \\
2.85 & 101.77 & 53.64 \\
2.84 & 101.77 & 60.05 \\
2.84 & 101.79 & 70.41 \\
2.81 & 101.76 & 35.36 \\
2.85 & 101.81 & 54.25 \\
2.81 & 101.82 & 58.22 \\
2.86 & 101.79 & 52.73 \\
2.85 & 101.80 & 71.02 \\
2.84 & 101.80 & 79.25 \\
2.84 & 101.81 & 63.09 \\
2.84 & 101.81 & 68.88 \\
\hline
\end{tabular}

\section{DISCUSSION}

The BBN area is approximately $416 \mathrm{~km}^{2}$ and located in the upstream of Sungai Langat and Sungai Linggi. Originally, BBN was a primary forest before been converted to rubber and oil palm estate and later converted to commercial and industrial area in early 1990 s. Land cover change for areas within catchment such as Mantin, Labu, Sepang and Nilai will influence the surface flow rate, sedimentation, discharges and also the quality of water sources, apart from land surface exposure to 
surface erosion agent. Considering the current and future needs, the developer has developed the $\mathrm{BBN}$ areas sustainably by providing reservoirs for flood and erosion control. Reservoirs divert the flow direction for the present drainage system (diversion) according to segments divisions to related sub-rivers of Sungai Langat like Sungai Jenderam, Sungai Mahang and Sungai Pajam in order to slow down the water flow and to avoid flash flood. This is because the catchment shape for the main river sub-basin in $\mathrm{BBN}$ is circular which influence the water flow to downstream in higher rate compared to the elongated shape. Effort to flow water into Sungai Langat instead of Sungai Linggi (monthly average $20 \mathrm{~m} \mathrm{sec}^{-1}$ maximum value $100 \mathrm{~m} \mathrm{sec}^{-1}$ ) is reasonable with the size of the river that capable of receiving high discharge rate with monthly average rate of $50 \mathrm{~m} \mathrm{sec}^{-1}$ (maximum rate hitting $200 \mathrm{~m} \mathrm{sec}^{-1}$ ) (based on discharge station data in Dengkil and Sua Betong).

Developments planning taken into account the need to maintain water resources for certain areas based on past pattern of water availability, the quality, requirement level, climate factors and influences by human activities (Abdul Aziz and Burn, 2006). Besides that rainfall trend and its variation need to be considered by hydrologists on the feature changes of certain areas that are subject to development planning to fulfil human needs (Kundzewicz and Robson, 2004; Burn et al., 2004; Lindstrom and Bergstrom, 2004).

Actions and planning carried out by the developer are preventive measures to prevent possible negative impacts downstream. The 26-reservoir ponds (including the drainage system) play a significant role as an early mitigation measure for areas that has been covered following land development to decrease the river flow rate (discharge rate), reduce deposition rate by providing sediment reservoir and to maintain the water flow level in the drainage system (flow regulation) for flora and fauna conservation. With average rainfall rate that is medium compared to other areas in West coast of Peninsular Malaysia, the expectation of the developer deemed suitable by providing medium-sized reservoir tiered according to the topography level to avoid the incident of flash flood and overflow.

\section{CONCLUSION}

Perusal and understanding of the hydrology aspects of drainage basin is subject to comprehensive land development planning that are necessary to prevent environmental impacts on depletion of sources, water supply and flood. Apart from that detailed examination on current and future prospect related to climatic characteristics change (rainfall) and its impact on water sources are also needed so that suitable strategies can be carried out to ensure nature conservation. New industrial town of $\mathrm{BBN}$ which located at the upper part of river catchment was developed based on conservation features. BBN can be used as a model for the development planning of other river basin areas that are subject to development in upstream areas.

\section{AKNOWLEDGEMENT}

This study was funded by UKM-ZZ1-05-FRGSO001 2006.

\section{REFERENCES}

Abdul Aziz, O.I. and D.H. Burn, 2006. Trends and variability in the hydrological regime of the mackenzie River Basin. J. Hydrol., 319: 282-294.

Burn, D.H., J.M. Cunderlink and A. Pietroniro, 2004. Hydrological trends and variability in the Liard river basin. Hydrol. Sci. J., 49: 53-67.

Hewleet, J.D., 1982. Principles of forest hydrology. Hydrol. Sci. J., 49: 69-83.

Kundzewicz, Z.W. and A. Robson, 2004. Change detection in hydrological records-a review of the methodology. Hydrol. Sci. J., 49: 7-19.

Lindstrom, G. and S. Bergstrom, 2004. Runoff trends in Sweden 1807-2002. Hydrol. Sci. J., 49: 69-83. 